\title{
A Mixed Method Study about the Experiences of Students and Lecturers of Work-Integrated Learning in Teacher Education
}

\author{
Elize du Plessis \\ Department of Teacher Education, \\ UNISA, Republic of South Africa
}

\begin{abstract}
The notion of "openness" in terms like "open distance learning” (ODL) often lacks conceptual rigidity, resulting in the careless use of the notion in whatever context distance learners find themselves. A case in point is work-integrated learning (WIL) of distance learners, for example in the teaching practice of UNISA's education students. Work-integrated learning (WIL) is a defining element of a holistic educational strategy known as cooperative education, which advocates the formal integration of structured real-life experiences (workplace or community service) into the overall programme curriculum. To investigate the current model of teaching practice at a distance learning institution, data were collected by means of a literature review (including constructivist learning as theoretical framework), semi-structured and open-ended questions in interviews. The research highlights the need for more training in lesson planning, specifically training in specific learning areas, learning outcomes and assessment. It is also clear that South African WIL will need to be supervised in all stages of implementation to ensure that the set objectives are realised. The study highlighted the importance of practical teaching, as well as specific problems experienced by students and lecturers during practical teaching in an ODL context.
\end{abstract}

\section{Introduction}

Several studies in distance education (DE) (teacher education) reveal that the organisation of practice teaching for teacher trainees presents both logistical and educational difficulties [1]. The main idea that one has to understand about open distance learning (ODL) is that all systems have to be integrated to support the academic enterprise and the student. One of the biggest problems for DE, particularly in our context as a developing country, is overcoming transactional distance. There is a transactional gap between students and the institution, between students and lecturers/tutors, between students and courseware and between student and student. It is the cognitive space between learning peers, teachers and content in a DE setting [22]. The University of South Africa (UNISA) with it is nearly 360000 students, for example, is faced with unique and formidable challenges - including student teaching practice - in the training of teachers. Lecturers at UNISA were urged by the Higher Education Quality Committee (HEQC) to improve the students' teaching practice experience. According to the HEQC [13] requirements, selection of schools, placement of students, training of mentors and mentoring during the teaching practice period and assessment of students' competence and feedback to the university needed improvement [13].

Teaching practice is a form of WIL, which is an extinct form of learning experience. All components of students' teaching practice must be based on the key features of WIL, which are alluded to later on. Universities also need advice on insurance and the safety of students, for example. Another issue that cannot be ignored is that of disadvantaged students who may have less access to work placements [33]. WIL programmes must continue to cater for these groups since they derive significant benefit from participation.

The specific aims of this article are to:

- Evaluate the current model of teaching practice at UNISA

- Extract the views of students and lecturers regarding their experiences of teaching practice and school visits

- Investigate if teaching practice (as WIL) can indeed function successfully in the DE or ODL context? 
The findings of this study are intended as guidelines for improving the practical teaching component at distance learning institutions.

In the next section, the background to the problem and relevant theory are given. Thereafter the research design and data-analysis are presented, followed by a discussion of the findings and key recommendations on the teaching practice component of distance learning students.

\section{Problem statement}

WIL usually falls into three primary categories, namely, industry internships, fieldwork and projectbased placements [2]. This article will emphasise the first category in an attempt to reach a better understanding of the relationship between open and distance learning (ODL) and WIL processes. It is a challenge in DE to be able to provide hundreds of thousands of students from South Africa and beyond with access to higher education and to supervise students while they are busy with their teaching practice [13]. The following questions thus need to be answered:

What are the students' and lecturers' views on teaching practice and problems they experience while doing their teaching practice and school visits and to what extent can teaching practice challenges in a distance learning context be overcome by adhering to the features of WIL? In other words, how can student teachers acquire the necessary knowledge and skills to perform by engaging and interacting in the school "situation" under the guidance of expert teachers, thus empowering themselves and making the abstract knowledge they acquired through their studies meaningful for application in real-life situations (schools)?

To address these challenges the constructivist theory on teaching and learning was used as theoretical orientation. WIL and ODL will also be discussed as part of the theoretical orientation.

\section{Theoretical orientation}

\subsection{Constructivist perspective on teaching and learning}

The constructivist perspective was used in research by Piaget [24], John Dewey [10], Vygotsky [35] and the gestalt psychologist, Bruner [3]. This approach favours student-centred teaching and learning and putting the students' own understanding at the centre of educational events [39]. Constructivists argue that students should deal with complex situations rather than merely simplified problems and basic skills drills.

Most constructivists share two main ideas: (1) that learners are active in constructing their own knowledge, and (2) that social interactions are an important part of knowledge construction [4]. Constructivist learning does not focus on individual learning, but rather on working together to negotiate or construct meaning. To accomplish this, students need to talk and listen to one another.

Constructionists are also concerned with how common-sense ideas, everyday beliefs and commonly held understandings about people and the world are communicated to new members of a socio-cultural group [11]. Relationships between and among teachers, students, families and the community are the central issues. Windschitl [38] suggests that the following activities encourage meaningful learning

- Students' ideas and experiences relating to key topics such as lesson plans, teaching media and assessment criteria are elicited, followed by the fashioning of learning situations which help students to elaborate on or restructure their current knowledge.

- Students are given ample opportunity to engage in complex, meaningful, problem-based activities, such as designing lesson plans during the teaching practice periods at schools.

- Students receive external support in the form of coaching from supervisor teachers/mentors, as well as hints, feedback, models and reminders.

- Students work collaboratively. They are encouraged to participate in task-oriented dialogue with one another.

- When planning and presenting lessons, students are asked to apply knowledge in diverse and authentic contexts to explain ideas, interpret texts, predict phenomena and construct arguments based on evidence, rather than to focus on the acquisition of predetermined "right answers".

- Supervisor teachers/mentors employ a variety of assessment strategies to understand how students' ideas are evolving and to give feedback on the processes and the products of their thinking.

According to Collins, Brown and Holum [7], students should reflect on their progress and compare their teaching to their earlier performances and to the performance of the supervisor teacher.

These guidelines taken from the constructivist perspective on teaching and learning should be applied to teaching practice. This will help students 
to put plan into practice and to learn from experience, which bring us to WIL.

\subsection{Principles and key features of work- integrated learning}

WIL is a defining element of a holistic educational strategy known as cooperative education, which advocates the formal integration of structured real-life experiences (workplace or community service) into the overall programme curriculum. It is a departure point for applied learning that focuses on work experience under supervision and/or mentorship of the workplace. It is a learning programme that focuses on the application of theory in an authentic, work-based context [18].

WIL is thus a distinct form of learning experience, which incorporates the workplace setting as a component of learning [2]. Students learn from authentic work experiences and are required to produce evidence of such learning in the form of portfolios, projects, reports, logbooks, applied assignments and/or presentations to panels for evaluation purposes. Some of the fundamental features of WIL (for the purpose of this article) are as follows:

- The appropriate vocational community is a key role player in the curriculum decision-making process.

- The learning outcomes determined during the curriculum development process are translated into WIL guidelines for the student and the workplace mentor. The learning materials include assessment tasks, criteria, and so on.

- The university actively engages in marketing cooperative education in order to secure sufficient and suitable WIL placement opportunities. Learner support staff further facilitates the placement of unemployed students.

- The university mentors individual students and plans and enters into contracts with institutions.

- The university manages the regular and systematic in situ monitoring and assessment of WIL, and remains responsible for verifying the attainment of the predetermined WIL outcomes by individual students.

For learning to come from the experience of participating in WIL activities, these activities, according to Bennet [2], must provide a meaningful experience that is intended and accredited by the institution.
The aims of WIL are:

- to expose students to the real world of the workplace while studying;

- to assist students to gain general work experience in a professional work environment;

- to help students develop a range of valuable generic skills; and

- to make the transition from student to employee easier [18].

WIL seems to be the ideal way for the student to become an effective teacher because, according to Milne [21], the student interacts with the organisation, staff and other role players during practical teaching. Students learn by observing and participating and by intervening and influencing what is taking place. The problem still remains, however, that most of these features are not currently being implemented in teaching practice. The organisation of teaching practice in an ODL environment has huge challenges.

\subsection{Work-integrated learning in the distance education context}

According to the Open University in the United Kingdom, 'distance learning' is studying on one's own, at home or wherever is suitable and 'open learning' entails studying in one's own time. You read course material, work on course activities, and write assignments [29]. ODL is a multi-dimensional system, which aims to bridge the time, as well as the geographical and transactional distance between student and institution, student and lecturer/tutor, student and courseware, and student and peers. Ideally students should be in the position to gain the prerequisite experience within their own environment.

Internationally, the trend in most countries is to use DE to increase accessibility and participation rates. Central to this endeavour is a sensitivity related to accessibility, retention, throughput and relevance. An important distinction can, however, be made between $\mathrm{DE}$ which begins with a method (a way of teaching) and open learning which begins with a purpose (i.e. developing education delivery strategies).

From its earliest conceptions, DE has always been conceptualised from the "provider" perspective, yet with features of flexibility and supportive communication [34]: 
- The theory of Wedemeyer [36] emphasises the application of technology for promoting democracy and independent study through extended access and interactive communication.

- Holmberg [14] distinguishes the guided conversation character of $\mathrm{DE}$, manifesting in various forms of study at all levels so as to facilitate learning. Although there is mostly no direct contact, students benefit from the conversation contained in pre-produced courses, and from interactive communication with their lecturers.

- Moore [22] highlights the maintenance of a transactional balance between the variables of dialogue, structure and learner autonomy. The transactional balance is dependent on proper communications media, the design of courses, the selection and training of lecturers, and the learning styles of students.

- Peters [26] emphasises the principles of industrial organisation whereby technology enables large numbers of students to access university study due to online learning possibilities in a knowledge-based economy characterised by a digital environment.

It is clear that $\mathrm{DE}$ is unthinkable without flexibility, a certain "openness". This aspect is clearly implied even in a typical institutional policy description of DE: "Distance education is a set of methods or processes for teaching a diverse range of students located at different places and physically separated from the learning institution, their tutors, as well as other students” [31].

As part of the flexibility of DE, WIL has always been viewed as an accepted, even highly desirable part of the DE curriculum. It is thus not surprising that an established DE institution like UNISA has a dedicated policy on experiential learning, inclusive of WIL [33]. In the preamble to this policy, experiential learning is described as

.... the process of making meaning from direct experience and an interplay between theory and practice. It is learning through reflection on doing. Experiential learning as an educational method facilitates the exposure of students to realistic experiences and important contextual characteristics of relevant disciplines [33].

The policy (ibid.) states that experiential learning can include WIL, and it denotes the integral part which the DE institution plays in the latter in the following description: "WIL means educational activities that integrate theory and practice in workbased contexts. These activities are assessed by the university and contribute to exit-level outcomes of a qualification".

Several studies on teacher training through DE reveal that the organisation of practice teaching (i.e. WIL) for teacher trainees presents both logistical and educational challenges [1]. Problems facing practical teaching via DE include the placing of students at approved schools, mentoring and supervising them during school visits, building relationships with all stakeholders, assessment and feedback. One of the biggest problems for DE, particularly in our context as a developing country, is overcoming transactional distance. Moore [22] defined transactional distance as "a psychological and communications space to be crossed, a space of potential misunderstanding between the inputs of instructor and those of the learner" [12]. In practical terms, such a transactional gap can exist between students and the institution, between students and lecturers/tutors, between students and courseware and between student and student. Student experiences of WIL in the DE context are self-evidently a valuable source of information in determining the extent of this transactional gap. The questions are: To what extent is WIL really effective in the DE context, and if the extent is indeed significant, what are the pertinent opportunities and challenges? Directly related to teaching practice, the question is: What are the students' and lecturers' views on teaching practice in the DE context, what problems do they experience, and to what extent can teaching practice challenges in a distance learning context be overcome?

In the following sections, the researcher will report on the findings, which envisaged finding answers to these questions.

\section{Case study}

\subsection{Practical teaching at UNISA}

One of the biggest problems facing DE, particularly in our context as a developing country, is overcoming transactional distance. Print study packages, the internet (digital study material) and technology can bridge the transactional distance if designed and applied by competent lecturers and tutors. Tutors and face-to-face tuition, such as practical teaching in the classroom situation, are beginning to play a more prominent role.

A point of criticism in the report of the review panel for the Higher Education Quality Committee (HEQC), who did an auditing of the University of South Africa (UNISA) during 2007, relates to the practical teaching component in UNISA's B.Ed. and PGCE programmes. The question that has to 
be answered is how can UNISA improve its practical teaching programme? Is WIL a possible solution to this problem and what are the implications? UNISA uses WIL as an umbrella term. It includes teaching strategies such as clinical training, teaching, internships, professional practice, experimental training/learning and workbased learning.

To reach the ODL ideal towards which the university is working, a few issues need serious attention:

- The three B.Ed. and three PGCE programmes presented by UNISA have a total of 16000 registered students, all of whom need to do at least 10 weeks of practical teaching. Other options, such as a one-year practical teaching (bearing 120 credits) period, are under scrutiny.

- The problem is, however, not so much the time frame of the teaching period as the placement and assessment of the students. One must also bear in mind that, while UNISA has been training teachers (including teaching practice) for many decades and has much relevant expertise, it has not kept abreast of new challenges such as technology, the teaching profession, community needs and HEQC imperatives.

- Problems facing practical teaching via distance (ODL) include the placing of students at approved schools, mentoring and supervising them during school visits, building relationships with all stakeholders, assessment and feedback.

- The relevant academic departments provide monitoring guidelines and assessment criteria, and remain ultimately responsible for summative assessment and for ensuring that students have acquired the required competence. The problem is, however, the lack of appropriate resources and support systems to accomplish this.

\subsection{Research method}

The researcher employed a mixed method approach using a phenomenological research design to obtain an understanding of the views of students and lecturers regarding teaching practice. According to the principle of mixed research, researchers should collect multiple data using different strategies, approaches, and methods in such a way that the resulting mixture or combination is likely to result in complementary strengths and non-overlapping weaknesses [15]. This shows that the qualitative research paradigm does not have to necessarily displace the quantitative paradigm, but rather the two can 'live' together Niaz [23].

Purposive sampling was used to select 40 students enrolled for teaching practice modules in the B.Ed. and PGCE programmes at UNISA, as well as ten lecturers. The students selected for the research were from different schools, namely from multicultural, single-culture, parallel-medium, dualmedium and single-language schools. Some students were from suburbs, some form rural areas and some from city centres. Data were gathered using qualitative research interviews. Twenty-three (23) of the selected students were enrolled for the B.Ed. programme and 17 selected students were enrolled for the PGCE programme. The intention was to elicit the students' views on teaching practice and problems they experience while doing their teaching practice. Lecturers were all from the same department at UNISA. The students were asked three semi-structured (biographical information) and 12 open-ended questions. The questions were geared to elicit views on the study material as part of their preparation and the school context (including mentorship and assessment) as it affected teaching practice. Participants were asked how they experienced the role of the school context where teaching practice takes place, the role of the teacher (as mentor) and the way assessment is done. For each of the above al the participants were asked: What worked well? What did not work well? What can be recommended?

\subsection{Trustworthiness}

Various measures were taken to ensure that the results are a function solely of the participants and not of possible biases and motivations of the researcher. A lengthy data collection period was used to conduct the research. The 40 participants drawn from schools with poor human resources as well as from schools with rich human resources represented a meaningful variety of cultural groups and contributed through personal interviews. After every interview the data were transcribed. This gave the opportunity for continual data analysis and comparison to refine ideas. With regard to the participants' language, the interview questions were phrased in accordance with the participants' language competence and were therefore less abstract. Observations and interviews were conducted in schools where teaching practice reflects the reality of life experience. Furthermore, by a process of continuous self-monitoring and submission of all phases of the research process to rigorous questioning and re-evaluation, the researcher took care to guard against being biased. Transcriptions and field notes were used to record 
verbatim accounts. Descriptions were almost literal and any important terms were those used and understood by the participants. Verbal data were captured by using tape recorders during the interviews.

\subsection{Findings}

The data rendered useful information on the role of UNISA, the school and the student. The biographical information of the students was as follows:

From the 40 students, $37.5 \%$ were male and 62.5\% were female students.

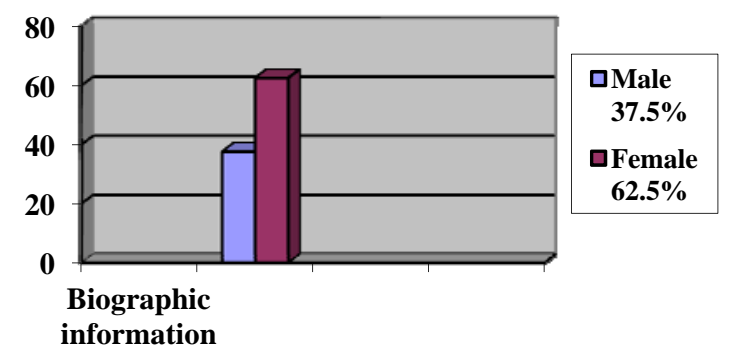

Figure 1. Biographical information of the students

Purposeful sampling was used to select the 40 information-rich participants whose ages ranged from 20 to $40+$. The participants were also representative of different cultural groups.

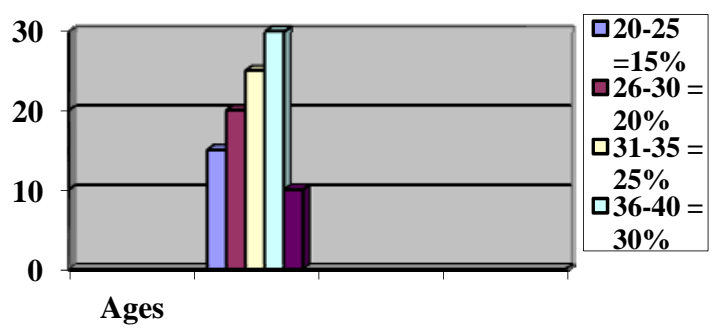

Figure 2. Age information of the students

The data-analyses highlighted two aspects of teaching practice, namely study material and school context.

\subsection{Study material for teaching practice}

The data collected indicated that students complimented UNISA for clear study material and tutorial letters and well-prepared documents based on a syllabus, which was in line with the National Curriculum Statements documents. The wellstructured lesson plans with their clear guidelines and practical examples and ideas to use in classroom settings, all of which made lesson preparation easy, were also commended. The clear layout of study material served as a broadly based framework for teaching practice. A 43-year-old female student from a rural single-medium high school knew what "is expected of me as student" and she also admitted that this meant she was expected to read more. A 35-year-old female student at a well-resourced private school felt that the UNISA's material supplemented existing knowledge. A 25-year-old male student from a well-resourced school felt that the theoretical foundation provided good preparation for most practical situations. He knew exactly what was expected from him for practical teaching: "This translated the theory into practice very nicely for me”. According to the participants, the study material also taught them how to do assessment and they found the learning outcomes essential tools.

On the other hand, some of the students indicated that guidelines were not sufficient. One student felt that the academic introduction to practical teaching was poor. More information regarding learning outcomes and assessment standards was required. A 23-year-old male student from a parallel-medium school remarked that he experienced a discrepancy between the guidelines of the Department of Education and UNISA's guidelines regarding the content of a lesson plan. Another student stated that she was uncertain about how to complete the Learning Area Didactics section of the workbook and requested more information regarding terminology. There was a lack of in-service training to inform students about what was expected of them in each of the following: Learning Area Didactics and Subject Didactics.

According to one student, since the material did not explain well enough how to improve lessons, he had been compelled to ask other teachers for clarification of terminology used in the course and for assistance with understanding materials/concepts. The students would prefer to do lesson plans electronically as it is timeconsuming to write out lessons by hand.

The following recommendations were given by students: students requested information about learning outcomes and assessment standards; they needed examples, specific guidelines giving the lecturer's expectations, lists of recommended books to use for school subjects and more teacher involvement. Students need more guidelines on assessment and assessment strategies, as well as guidelines on preparing lessons. 
In terms of whether their studies prepared them for teaching, most students believed that they were prepared in most respects.

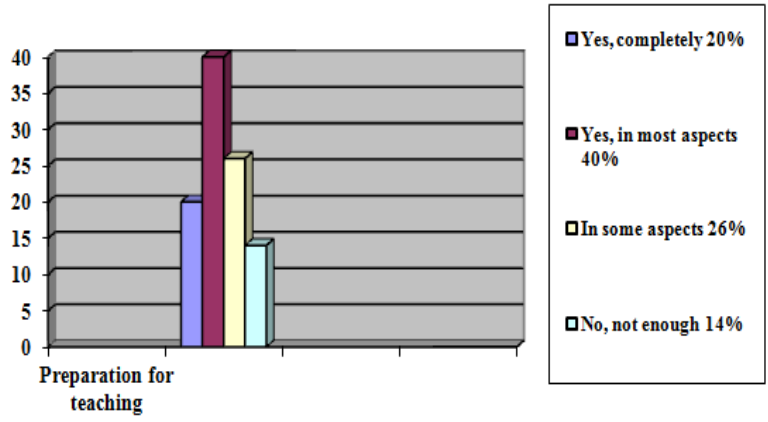

\section{Figure 3. Information on preparation for teaching}

\subsection{The school context}

Regarding the schools in which students were placed and their mentors, the following responses were given by students:

- Students were welcomed by school principals and received all the necessary support. One student in a rural well-resourced single-medium high school said that she felt totally involved in the school - "just like part of the school". One student in a well-resourced model C high school said: "Practical experience (standing in front of a class) gives you an understanding of the reality of teaching”. One student placed in a well-resourced private school, commented on an excellent, well-established team that gave him support through the beginning stages as well as material for lesson plans. Most of the students found the schools very supportive: they felt part of the school and it was great for them to be involved in practical teaching. Another student, a 34-year-old male from a private wellresourced school testified that the teaching practice in schools worked well: "I can fill a notepad because there was exciting things that happen, or different things that happen, different situations come up which is really what is fascinating about the whole teaching environment which is so dynamic, like it changes all the time and you never know what is going to come round the corner next."

- Teachers were found to be accommodating and helpful in general, although some students felt that they had been thrown into the deep end. Some students had a range of teachers and were exposed to various teaching approaches. Most of the students were exposed to the full spectrum of teaching activities and were treated as true colleagues. Students felt that most schools were professional, with good resources like computers, whiteboards and access to the internet, science laboratories, and textbooks for teachers and learners. All the same, a minority of students felt unwelcome and sensed that teachers at schools felt threatened by them as students. One student indicated that schools need to spell out their expectations of students.

Before individual students can go to specific schools, they must find out whether their subject is offered at the school. Most of the rural and townships schools have internet facilities, but lack other resources, such as books in their libraries. Schools are willing to accept UNISA students for their teaching practice. It is very difficult to do teaching practice in a number of schools, as required by the HEQC, because lesson themes, for example, differ from school to school. Moving from one school to another, one would have to start all over again with lesson planning. Not all the schools have trained mentors to supervise students. Mentors or heads of department who do the assessment during teaching practice do not always follow specific guidelines. The assessment differs for Subject Didactics and Learning Area Didactics.

The findings reflect a triad of interdependent role players in the teaching practice arena: UNISA, the school and the trends and challenges associated with the reality of teaching practice for DE students enrolled for the B.Ed. and PGCE programmes at the university. The following conclusions can be made:

- Reduce student numbers. One way of doing this will be to introduce admission examinations, limit registrations and restructure the B.Ed. and PGCE programmes.

- Pay more attention to partnerships between the university and individual schools. An effective partnership should deliver a range of outcomes that provides benefits for all parties (Smith et al. 2000, in Cushen [9].

- Set up a mentoring support system in every school and extend the capacity of the existing training and mentoring programme.

- Mentors should be given specific guidelines and assessment criteria for assisting and evaluating students.

- Implement a placement scheme, which will provide relevant and adequate student support as well as sufficient resources to make the programme successful. More funding and academic and administrative staff is needed. 
- Students should be given more time to do observation before they start presenting lessons.

- Establish a support department to deal with travel arrangements and the placing of students at various schools.

- Improve study material to prepare students more effectively for WIL. The study material should include specific guidelines and examples.

- Pay more attention to the sequence in which students take modules. They must, for example, do modules on programme development and assessment before they do modules on subject didactics, learning area didactics and teaching practice.

- Implement a standardised system for a number of lessons in Learning Area Didactics and Subject Didactics.

- Standardise the forms that students and mentors need to complete as part of their assessment while doing their teaching practice.

- Support students by observing classroom interactions, improving communication between lecturers and students, and assisting them with problem-solving skills.

- More research should be done to develop a WIL model to ensure that all stakeholders are involved in the design process. More time should be allowed for preparation, interpretation, supervising and assessment.

HEQC requirements have indicated that the organisation of UNISA teaching practice needs to be improved in many ways relating to placement of students, mentoring and assessment of students in particular. Regarding UNISA's preparation of students, it is clear that the main issues that need to be addressed relate to greater clarity on what would be expected of them (learning outcomes, assessment criteria, guidelines on how to develop lesson plans - including practical examples, and lesson content).

Responses from lecturers will be discussed very shortly in the next section.

\subsection{Regarding lecturers' experience of teaching practice:}

Biographic information of lecturers was as follows: $80 \%=$ Female and $20 \%=$ Male

Ages of lecturers: $40 \%$ = between $40-49$ and $60 \%$ $=50$ and older

Lecturers' position: Senior Lecturers $=60 \&$ and Professors $=40 \%$
The following comments were made by lecturers on what worked well during teaching practice and school visits:

- Arrangements made by lecturers themselves

- Principals who welcomed lecturers and made them feel at home

- Visiting 2 students per day worked well

- Contact with students in your subject was significant

- One to one communication with a student was purposeful

Lecturers were also asked what did not work well. The following remarks were made:

- According to some of the lecturers logistical problems were some of the main complaints. One lecturer had to drive a distance of two hundred and forty kilometres

- Finding five students in one school who have all received their placements letters and are doing the same course, but a lecturer who has been deployed all the way from Pretoria should just assess only one of them, was very frustrating for both the lecturer and the students

- According to another participant a number of students have not been assigned mentor teachers in the schools and some do confess that they "are not really sure" what they should do at the schools

- Problem with arrangements according to principals and students

- According to a male respondent: to visit a grade one teacher when you lecture in the FET phase is problematic

- Time consuming to phone students and do arrangements

- Placements of students: One 50+ years respondent said: "I could visit more students when students could contact me directly as the placement office lists are incorrect, students far from each other and often already finished their time at school"

- Work pressure: hours don't indicate of what is really done

The following recommendations were made by lecturers:

- Lecturers should either visit as groups so that they cover a good number of students in one week or two

- A list of students in the same school should be compiled 
- Forms should be left with the student to improve his/her performance

- Supervisors should visit schools in rural areas they need support more

- Teaching Practice arrangements must be available earlier in the year

- Lecturers want to visit their OWN students and CHOOSE which area they want to visit

- A Unit for Teaching Practice with lecturers who do nothing but Teaching Practice should be established

\section{Recommendations}

The following recommendations serve as overall recommendations for ODL institutions involved in teaching practice of students:

- Meet industry needs

- Make sure that WIL is intentional, organised and accredited

- Oversee the placement, including orientation and coaching of the student

- Provide a safe working environment

- Communicate with the WIL co-ordinator for any work-related issues involving the student

- Complete work assessment forms on the student's performance

- Discuss the student's progress and meet with the WIL co-ordinator should a site visit be arranged

- Make sure that students develop a truly integrated approach to learning through a combination of academic and work-related activities

\section{Summative remarks}

From the empirical evidence it was concluded that problems in teaching practice (as WIL) in the DE context can all be linked to lack of proper information and clear guidelines. In sum, the empirical evidence provided a clear verdict that teaching practice (as WIL) can indeed function successfully in the DE context, and specifically so if the following requirements are heeded to:

- Practical classroom needs are met

- Teaching practice is intentional, organised and accredited

- The placement, orientation and coaching of the student is effectively overseen

- A constructive working environment is provided

- There is open communication between the teaching practice co-ordinator and the student on any work-related issues involving the student
- Work assessment forms on the student's performance are comprehensively completed

- There are frank discussions of students' progress in meetings with the teaching practice co-ordinator and during site visits

- There are effective measures to ensure that students develop a truly integrated approach to learning through a combination of academic and work-related activities

All of these requirements point to teaching practice (as WIL) as a local, well-planned, highly structured and meticulously scheduled mode of learning, with hardly any nuances of "openness" in the sense of being student-driven.

\section{Conclusion}

The findings of this research and the discussions regarding the reality of teaching practice and WIL at an ODL institution have given insight into the students' and lecturers' experiences in the school context. WIL as an attitude or paradigm that seeks to make use of and explain a number of theories has been addressed. The research, based on comments from students and lecturers, highlights the need for more training in lesson planning, specifically training in specific learning areas, learning outcomes and assessment and it also highlighted logistical problems. However, as hinted to already, the study of the key features and practical experiences of WIL in the DE context has brought the researcher to the realisation that the concept ODL should be used with much more care. It is clear from the empirical data and discussions that the student-driven features of ODL and the highly structured, organised and scheduled features of WIL (as indicated earlier) are worlds apart. During the WIL part of their learning, students of an "ODL institution” cannot be regarded as ODL students. This constitutes an untenable conceptual anomaly. Such anomaly is, however, absent when WIL is contemplated and practised in the flexible provider mode of DE (i.e. without undue promises and expectations about the "openness" of learning).

While WIL makes perfect sense in a DE setting, as already pointed out, the question is: Can WIL (as a "closed", highly structured mode of learning) fit into the highly popular educational wrapper of ODL? Even if UNISA succeeds in overcoming the present huge challenge of successfully aligning all the different processes, systems and procedures (Prinsloo [25]) in the interest of optimal service delivery, the idea of UNISA ever reaching the stage of "student choice in content, time, place, pace of learning, method of instruction and nature of 
assessment” seems fictitious for many practical, societal and economic reasons. With reference Moore [22] and Wei [37] indicates convincingly that the ODL notion may not be sustainable in under-developed and developing economic environments, for reasons of lacking professional and financial capacity.

Restating the impetus that lead to this article, the researcher is strongly of the view that DE and WIL constitute the proven, established and ideal conceptual frameworks for the design and implementation of teaching practice in the College of Education at UNISA, but not as an ODL institution.

\section{References}

[1] Aldridge, J., Fraser, B. and Ntuli, S. 2009. Utilising learning environment assessments to improve teaching practices among in-service teachers undertaking a distance-education programme. South African Journal of Education, 29(2), 147.

[2] Bennet, K. 2005. Learning in the workplace: Applying theory to practice (and back again). Work-integrated learning symposium 2. Paper presented at the University of Technology, Nov 2006, Brisbane, Australia.

[3] Bruner, J. 1973. Going beyond the information given. New York: Norton.

[4] Bruning, R.H., Schraw, G.J., Norby, M.M., and Ronning, R.R. 2004. Cognitive psychology and instruction, 4th ed. Columbus, $\mathrm{OH}$ : Merrill.

[5] Calway, B.A. 2006. What has Work-Integrated Learning Learned? - A WIL philosophy. Swinburne University of Technology: Lilydale: URLbcalway@swin.edu.au (2 March 2010).

[6] Cole, M. 1985. The zone of proximal development: Where culture and cognition create each other. In Culture, communication, and cognition: Vygotskian perspectives, ed. J.V. Wertsch, 146-161. Cambridge University Press: London.

[7] Collins, A., Brown, J.S. and Holum, A. 1991. Cognitive apprenticeship: Making thinking visible. American Educator, 15(3), 38-39.

[8] Crawford, K. 1996. Vygotskian approaches to human development in the information era.

Educational Studies in Mathematics, (31), 43-62.
[9] Cushen, J. 2005. Stakeholder perceptions of work-integrated learning: Analysis and recommendations. Doctoral dissertation (unpublished). University of Otago, New Zealand.

[10] Dewey, J. 1966. Democracy and education. Free Press: New York.

[11] Gergen, K.J. 1997. Constructing constructivism: Pedagogical potentials. Issues in Education: Contributions from Educational Psychology, 3, 195-202.

[12] Gorsky, P. and Caspi, A. 2005. A critical analysis of transactional distance theory. Quarterly Review of Distance Education, 6(1), 1-11.

[13] Higher Education Qualification Committee (HEQC). 2008. Audit report, 12 May. Council on Higher Education (CHE).

[14] Holmberg, B. 1989. Theory and practice of distance education. Routledge: London.

[15] Johnson, R.B. and Onwuegbuzie, A.J. 2004. Mixed Methods Research: A Research Paradigm Whose Time Has Come, Educational Researcher. 33, 14-26.

[16] Marshall, H. ed. 1992. Redefining student learning: Roots of educational change. Norwood, NJ: Ablex.

[17] Marshall, H.H. 1992. Reconceptualising learning for restructured schools. Paper presented at the Annual Meeting of the American Educational Research Association, April 1992, Tanta University, Egypt.

[18] Mbango, P. 2009. Work Integrated Learning (WIL).University of Johannesburg: www. uj.ac.za/marketing/workintegratedlearning/ tabird (19 May 2009).

[19] McIntyre, J. and Solomon, N. 2000. The policy environment of work based learning. In The policy environment of work based learning, eds. C. Symes and J. McIntyre. Society for Research into Higher Education and Open Press: Buckingham.

[20] McMillan, J.H. and Schumacher, S. 2001. Research in education: A conceptual introduction, 5th ed. United States: Priscilla McGeehon.

[21] Milne, P. 2005. A model for work integrated learning: Optimising student learning outcomes. Canberra: University of Canberra. 
[22] Moore, M.G. 1993. Theory of transactional distance. In Theoretical principles of distance education, ed. D. Keegan. Routledge: New York.

[23] Niaz, M. 2008. A Rationale for Mixed Methods (Integrative) Research Programmes in Education. Jounal of Philosophy of Education, 21(2), 287-305.

[24] Piaget, J. 1955. The construction of reality in the child. New York: Routledge and Kegan Paul.

[25] Prinsloo, P. 2011. The Achilles' heel of ODL. Focus, UNISA staff newsletter July 2011: 17.

[26] Peters, O. 2008. Distance education in transition: New trends and challenges. Shangai Higher Education Electronic and Audio-visual Press: Shangai

[27] Steinberg, C. 2006. Curriculum in contexts: An interpretation. ACE Residential Programme for Module EDUC 1004, University of the Witwatersrand.

[28] Strydom, H., Fouché, C. B. and Delport, C.S.L. 2002. Research at grass roots, 2nd ed. Pretoria.

[29] The Open University. 2009. Distance learning: www.open.ac.uk/news/distance-learning. shtml (19 May 2009).

[30] University of South Africa (UNISA). 2005. Work-integrated learning (WIL) policy. Van Schaik: Pretoria.

[31] University of South Africa (UNISA). 2008. Open Distance Learning policy. http://www.UNISA (26 October 2011).

[32] University of South Africa (UNISA). 2010. Work integrated learning: http://staff.unisa.ac.za/ index.jsp?link=http://www.unisa.ac.za/cmsys/staff/ default.asp?Cmd=ViewContent\&ContentID=3531 (19 February 2010).

[33] University of South Africa (UNISA). 2011. Policy: Experiential learning. http://www.unisa (21 October 2011).

[34] Van der Merwe, H. M. 2011. Mentoring teaching skills in higher education within the context of open distance learning (ODL). In press.
[35] Vygotsky, L.S. 1978. Mind in society: The development of higher psychological processes. Cambridge, MA: Harvard University Press.

[36] Wedemeyer, C. 1981. Learning at the back door: Reflections on non-traditional learning in the lifespan. Madison: University of Wisconsin Press.

[37] Wei, R. 2010. China's radio and TV universities: reflections on theory and practice of open and distance learning. Open Learning, 25(1), 45-56.

[38] Windschitl, M. 2002. Framing constructivism as the negotiation of dilemmas: An analysis of the conceptual, pedagogical, cultural and political challenges facing teachers. Review of Educational Research, 72(2), 131-175.

[39] Woolfolk, A. 2007. Educational psychology, 10th ed. Pearson: New York. 